\title{
MAIN CONCEPTS OF THE DOCUMENT MANAGEMENT SYSTEM REQUIRED FOR ITS IMPLEMENTATION IN ENTERPRISES
}

\author{
Vasila Soltanaga Abbasova ${ }^{1}$ \\ ${ }^{1}$ Department “Computer Engineering”, Azerbaijan State University of Oil and Industry, Baku, Azerbaijan \\ abdulvugar@mail.ru
}

ARTICLE INFO

Article history:

Received date 26.12.2019

Accepted date 16.01.2020

Published date 31.01 .2020

Section:

System Administration

DO I

10.21303/2313-8416.2020.001149

\section{KEYWORDS}

document

electronic document

electronic document management system

possibilities of electronic document

management systems

\section{A B S T R A C T}

This study is intended to study the system of electronic document circulation, its importance in the organization of documents. The main stages of the document lifecycle include creation, management/storage, access, retrieval, administration, reassignment, collaboration, distribution, preservation, disposal, storage. Definitions are given to such terms as "document", "electronic document", "control systems of documents" and "electronic document management systems".

The study examined the features, advantages, disadvantages and capabilities of the electronic document management system. Thus, the main characteristics of the electronic document management system include the following parameters: scalability, compatibility, due availability, dynamism. The main advantage of the electronic document management system is document flow automation, and the disadvantage is significant financial costs. And the capabilities of the electronic document management system include the provision of a user interface, capture, indication and receipt, annotation, storage and archive, distribution, workflow, security and integration of the system. The main requirements for the organization of documents are identified on the basis of this information.

(C) The Author(s) 2020. This is an open access article under the CC BY license http://creativecommons.org/licenses/by/4.0).

\section{Introduction}

Document management and project management are closely linked in an information-intensive project. The result of a project is usually a set of documents that describe the developed product, recycled process, or product to be delivered. If organization can identify the documents that generate the output and those that are needed at various intermediate stages, it can track the progress of the project using the document management system [1].

The concept of information manipulation will be explored by discussing the principles of document management systems. Document management systems have been established to receive process and transmit information [2].

\section{Literary review}

The Digital age has transformed the production and use of documents around the world. In The Information age, the process of entering, delivering, storing, receiving, and categorizing data is crucial. Enterprises are increasingly relying on automated, reliable solutions to ensure that their information is secure and accessible for effective management. A document management system is a computer system used to track and store electronic documents and/or images of paper documents. This term partially coincides with the concepts of content management systems, which are often seen as a component of enterprise content management systems and are related to digital asset management, document mapping, document management systems, and records management systems [2].

In a common language, the word document usually means a container of information containing written or drawn information for a particular purpose in structured form [3].

Traditionally, a document is a sheet of paper or a set of documents, such as a memo, a letter. Central to the idea of the document is that it can be easily transmitted, stored and processed as a whole $[2,3]$. 
Over the past decade, the term "document" has undergone radical changes in definition. This change is partly related to information technology. Thus, most of the documents processed in today's business world are stored as separate computer files and are considered as operating and e-mail systems as units [3].

\section{The aim and objectives of research}

The aim of research is to analyze the main concepts of the document management system necessary for its implementation in enterprises.

To achieve the aim, the following objectives are set:

1. Definition of document life cycle stages in electronic document management systems;

2. Definition of the main concepts of electronic document management systems;

3. Identification of characteristics, advantages and disadvantages of electronic document management systems;

4. Definition of the main capabilities of electronic document management systems.

\section{Life cycle of the document}

In digital language, a document is defined as a text file containing fonts, colors, formatting, and other elements. The document also has a life cycle that begins when it is created and ends with its deletion/preservation. A typical document lifecycle consists of the following steps [4]:

- Creation is the beginning of the document lifecycle.

- Management/storage. Once documents have been created, they are stored in data stores, archives, and other storage systems.

- Access. In this process, documents that were previously saved are searched using search tools.

- Extraction. In the life cycle of a document, retrieval refers to the task of viewing search results in various ways.

- Administration. Administration refers to the management of documents by users who have access to them.

- Reassignment. If any changes are made to the previous version of the document, a new document is created, which differs from the previous version, and thus the versioning process takes place.

- Collaboration. Collaboration and sharing of documents with other objects is called sharing in the document lifecycle [5].

- Distribution. The transfer of documents in a secure manner is called distribution.

- Saving involves saving past data for a certain period of time.

- Utilization. Documents should be securely destroyed upon expiration of their storage period.

- Storage. Some documents that are valuable and require use for a longer period of time require storage [4].

The main elements of the document lifecycle in the electronic document management system are listed above. Besides them there are also several auxiliary stages [6]:

- Document scanning creates an image of the document in a format that it is possible to view online.

- Document indexing is the process of linking or marking documents with different search terms. The thing of indexing is the path to documents.

- Document storage is the process of storing documents as electronic files. Online storage solutions have several obvious advantages over physical paper storage. First of all, online document storage systems allow to retrieve documents immediately.

- Safety of documents. Anyone can pick up a document from the table. But without permission, no one can access a system that has confidential documents [6].

Document protection goes far beyond who can access the system. With the online document repository, users can be given access to certain documents. So it is possible to protect the most important documents for specific individuals who need access to this information. It is possible to go even further by giving only some users access to all these documents, and others only part of the document [7]. 
Security also ensures that documents are saved and are not lost or damaged. The lost documents are obvious. Document search is the instant delivery of the right documents to the right people [7].

\section{1. Electronic document}

Information technology is capable of creating a new type of document - an electronic document in which graphic, text, CAD and multimedia objects (i.e. audio or video clips) can be stored [8].

Documents are processed and stored electronically not as physical objects, but as digital objects. A document is no longer a place where words are placed on a page, but is a set of elements or objects related to a particular topic, assembled together. Thus, a new definition of a document in the electronic age appears:

"An electronic document is an information container in electronic form that collects information from different sources in different formats on a particular topic to meet the needs of a particular person." [8]

The user can create an electronic document on a personal computer without creating a paper document. The electronic document can be identified, taken and stored on the Internet and Intranet in electronic form. One electronic document can be processed and transmitted to others on the network at the same workplace or even to users around the world via the Internet.

One advantage of the electronic document is that it is not necessary for each user to have the same media. An electronic document can be delivered in any format that meets your needs [8].

The document carries information in such a format that it can be distributed, stored and processed. Accordingly, anything stored in the available source is a document, whether it is a data source or a database. If to consider in electronic services everything that is stored in the database as a file or data object, in a broad sense it is a document.

It is unlikely that any documents are made by hand today, but many are still transferred by printing them and sending them to other parties by mail or courier, often using copying companies as intermediaries. A slightly more complex method is that documents are created digitally and transmitted digitally as email attachments. This accelerates the transfer of documents, but from the point of view of document management it hardly gives any improvement compared to the current situation, as finding a document on the personal computer of another person can be even more difficult than on its shelves.

Obtaining a document often, as a last resort, may require a person to deliver it. The most common method currently used is to use document management systems (DMs), where documents are stored centrally on the server, and users interact with this central repository through interfaces implemented using standard web browsers [9].

DMs has been and is still being developed to provide a repository where documents can be created, managed and stored for easier access by departments and users across the enterprise.

\section{2. Electronic Document Management System}

Document management as a technology and discipline traditionally extends the capabilities of a computer's file system. Document management is the process of storing, locating, updating, and sharing data to advance the workflow and achieve business results. Centralized data is sharing and storage across specific servers helps organizations gain effective access to information along with data protection. Programs and servers are used in the document management process [9].

Any large company will sooner or later feel the need for any electronic document management system (EDMs) to control their ever-increasing number of different documents and drawings. Companies often resist "this desire" and are constrained by the costs and complexities of implementing EDMs. Useful EDMs should not only control documents, but also ensure access to them throughout the company and even to clients or other project participants via the Internet. The EDMs should also centralize data in an easily accessible environment, allowing users to easily and quickly store, access, and modify information [9]. 
The standard EDMs features should continue to include the following functionality: Search Tool, Non-Source View, Red Line and Markup Function, Printing and Drawing, Document Workflows and Life Cycles, Revision and Versioning, Document Security, Document Relationships, Status Reports, Release/Distribution Management, and Remote Access.

The purpose of document management is to share information, making documents secure, accessible, recoverable, and interchangeable. The solution to this problem is electronic document management [9].

The primary purpose of the EDMs should be to assist in the recovery and retrieval of user files. Therefore, all EDMs shall have the following characteristics [10]:

- Scalability means that the system will still be useful when a large number of document collections are transferred to it.

- Compatibility entails the ability to adapt to new user requirements as they become available. As user workflow requirements change, classes can be defined or edited to meet these new standards.

- Remote Availability means it is possible to access files and documents from the office anywhere. The main purpose of this function is the portability and availability of documents.

- Dynamism. Search features are necessary to help the user quickly locate certain files. This feature goes hand-in-hand with scalability as it provides custom-scale performance as well as the number of documents in the collection [10].

Many companies use EDMs to standardize the way that information for anyone with the right credentials can find and access the document they want. The EDMs helps users to do their jobs more easily and to provide the company with security, data reliability, and workflow management. Many of these functions ultimately save time, simplify work, protect the investment invested in creating these documents, enforce quality standards, allow auditing and ensure accountability.

From Sun \& Aouad's perspective, electronic document management systems have the following advantages $[8,10]$ :

- Efficient location and delivery of documentation in general;

- Manage documents and data independently of source system or format;

- Ability to integrate computerized and paper systems;

- Control of access, distribution and modification of documents;

- Provide editing and markup tools.

On the other hand, electronic document management systems have disadvantages $[8,10]$ :

- Achieving the goals that are needed in today's environment requires major changes in the organization, including methods, systems, processes, and workflows.

- Technology and EDMs markets are changing rapidly, so it's worth looking for good ways to stay up to date with new applications, new vendors, new applications and new adoption approaches.

- All information must be in electronic format, which is either created electronically or scanned from a paper version. This includes handwritten notes and sketches, as well as large maps and complex drawings.

- High financial costs are required to implement the EDMs. Therefore, EDMs is used mainly by large companies.

\section{3. Capabilities of electronic document management systems}

While all document management systems provide the basics of scanning, searching, and displaying when it comes to implementing a solution of document management in the real world, the foundations of the system go far beyond the foundations. Document management systems that target multiple users, large volumes of documents, or multiple offices must meet stricter requirements. The following features are important when choosing a document management system for organization [11].

One of the most important factors for the success of a document management system is its ease of use.

The user interface is critical to ensure that personnel are accepted quickly. The system will only be widely used if it is simply collected, systematized and found. The best systems are 
user-friendly and flexible enough to adapt to how people already work in an organization, instead of forcing them to change their preferred way of working $[8,11]$.

Capture. For a document management system to improve business operations, it must cover all types of documents - paper, electronic, fax, audio and video, and many others - that are part of the organization's processes and procedures.

Instruction and receiving. The enterprise-quality electronic document management system is uniquely positioned to help solving the problem by helping employees quickly search thousands of documents to determine exactly what information they need.

Annotations allow users to add or remove document information without constantly changing the original image. Highlighting, stamps, editing, and notes are among the most common annotations. The security of the document management system should give the system administrator control over who can view annotations and view changes.

Storage and archive. Once the documents have been entered into the document management system, they must be securely stored. Management document storage systems must be able to adapt to changing technologies and the future growth of the organization. A universal document management system must be compatible with all currently available storage devices as well as new systems to ensure long-term retention and archiving of documents.

Distribution. EDMs should help provide the right information to the right people. The system allows multiple users to access the same files at the same time and helps distribute documents to authorized individuals both inside and outside the organization over an internal network.

Workflow. Workflow modules can enhance the benefits of document management by automating document routing across people, eliminating bottlenecks, and optimizing business processes. This additional functionality is critical for large branch offices, for organizations with headquarters and branch offices, and for organizations that plan to expand their system.

System security is an absolute necessity for any document management system. A strict security system should allow each authorized person to perform the necessary duties.

Integration. The introduction of new software and databases often poses logistical challenges for the organization's computer support staff. Document management programs should offer packaged integration tools to simply include images to minimize the burden on IT support staff. To minimize business disruption, it is important that the document management system seamlessly integrates with other software applications currently in use.

Technical reasons. The purpose of EDMs is not only to eliminate and organize paper, but also to manage all organizational documents [11].

\section{Results of a research}

Now, in Information age, there are various information technologies and systems. Each of them has its own purpose.

Electronic document management systems are available to automate document management. This article describes the most important concepts of these systems:

- A document is a container of information containing written or drawn information for a particular purpose in a structured form;

- A document management system is a computer system used to track and store electronic documents and/or images of paper documents;

- An electronic document is an information contained in electronic form that collects information from different sources in different formats on a particular topic to meet the needs of a particular person;

- The main purpose of the EDMs should be to assist in the recovery and retrieval of user files.

\section{Conclusions}

Following the study, the following conclusions can be drawn:

1. Key steps in the document lifecycle include creation, management/storage, access, retrieval, administration, reassignment, collaboration, distribution, preservation, utilization, storage; 
2. Basic concepts of EDMs: document, electronic document, control systems of documents and also electronic document management system;

3. The main characteristics of the EDMs include: scalability, compatibility, due availability, dynamism. The main advantage of EDMs is automation of document circulation, and the disadvantage - significant financial costs.

4. The capabilities of the EDMs include providing a user interface, capture, point and receive annotation, storage and archive, distribution, workflow, security, and system integration.

\section{References}

[1] Chto takoe dokumentooborot: principy+osnovnye etapy. Available at: https://biznesprost.com/rukovodstvo/chto-takoe-dokumentooborot.html

[2] Obzor sistem elektronnogo dokumentooborota. Available at: https://www.ixbt.com/soft/sed.shtml

[3] Sistemy elektronnogo dokumentooborota. Upravlenie znaniiami. Available at: https://sites.google.com/site/upravlenieznania$\mathrm{mi} /$ tehnologii-upravlenia-znaniami/sistemy-elektronnogo-dokumentooborota Last accessed: 15.02.2013

[4] Satton, M. Dzh. D. (2002). Korporativnii dokumentooborot. Principy, tekhnologii, metodologiia vnedreniia. Saint Petersburg: Azbuka: BMikro, 446.

[5] Zherebenkova, A. V. (2005). Dokumentooborot na predpriiatii. Moscow: Vershina, 384.

[6] Ipatov, V., Panov, V. (2010). Problemy sovremennykh sistem elektronnogo dokumentooborota i nekotorye podkhody k ikh resheniiu. Available at: https://www.osp.ru/news/articles/2010/0608/13033725

[7] Osnovnye funkcii sistem elektronnogo dokumentooborota.

[8] Elektronnii dokumentooborot. Available at: https://works.doklad.ru/view/6AN752uvwAI

[9] Elektronnii dokumentooborot: dostoinstva i nedostatki. Available at: https://knowledge.allbest.ru/programming/3c0a65625 b2bd78b4c53a88421206c37_0.html

[10] Elektronnii dokumentooborot. Available at: https://www.bestreferat.ru/referat-204453.html 